\title{
THE FOURTH INDUSTRIAL REVOLUTION RECONSIDERED: ON ADVANCING COSMOPOLITAN EDUCATION
}

\author{
Y. Waghid \\ Department of Education Policy Studies \\ Stellenbosch University \\ Stellenbosch, South Africa \\ e-mail: yw@sun.ac.za
}

\section{Z. Waghid*}

Senior Phase and Further Education and Training Department

e-mail:waghidz@cput.ac.za

\section{F. Waghid*}

Centre for Innovative Education Technology

e-mail: faiq@live.co.za

${ }^{*}$ Cape Peninsula University of Technology

Cape Town, South Africa

\section{ABSTRACT}

Since Klaus Schwab's (2016) phenomenal book, The Fourth Industrial Revolution, commonly depicted as $4 \mathrm{IR}$, the concept has significantly altered the multiple ways universities in (South) Africa look at or aim to address their institutional practices, most notably, teaching and learning encounters. Schwab's $(2016,7)$ reference to a "new technology" revolution that would transform the way humans interact in the world today is inspired by "emerging technology breakthroughs, covering wide-ranging fields such as artificial intelligence (Al), robotics, the internet of things (IoT), autonomous vehicles, 3D printing, nanotechnology, biotechnology, materials science, energy storage and quantum computing". In this leading article, we offer an argument in defence of prioritising what we refer to as the cosmopolitan human condition if any meaningful sense were to be made of what Schwab $(2016,7)$ refers to as the amplification of "fusion of technologies across the physical, digital and biological worlds". In reference to our understandings of university teaching and learning, we give an account of how such encounters ought to be looked at in light of the new fusion of technology idea - that is, 4IR.

Keywords: fourth industrial revolution, higher education, cosmopolitanism 


\section{A BRIEF BACKGROUND TO 4IR}

Undeniably, the previous three industrial revolutions liberated humankind from, firstly, excessive reliance on animals mostly for transportation purposes, which saw the invention of the locomotive steam engine and the concomitant construction of railroads resulting in the enhancement of food production, urbanisation and population growth, transportation and communication between 1760 and 1840. Secondly, between the nineteenth and twentieth centuries, mass production and communication among humans increased with the advent of electricity. Thirdly, since the 1960s onwards, the computer and digital revolution catalysed by personal computing (1970s and 1980s) and the Internet (1990s) led to an explosion in human communication. And, as claimed by Schwab $(2016,12)-$

\footnotetext{
"The fourth industrial revolution, however, is not only about smart and connected machines and systems. Its scope is much wider. Occurring simultaneously are waves of further breakthroughs in areas ranging from gene sequencing to nanotechnology, from renewables to quantum computing. It is the fusion of these technologies and their interaction across the physical, digital and biological domains that make the fourth industrial revolution fundamentally different from previous revolutions."
}

Simply put, from the above, it could be inferred that humans have been confronted with four industrial revolutions: the machine age, the age of electricity, the age of electronics, and the age of the Internet as platform (Peters 2017, 1). Again, as aptly summarised by Peters, the industrial revolutions occurred as follows:

\footnotetext{
"First an era dominated by steam and mechanical production, what we commonly know as the industrial revolution, followed by the mass production paradigm that dominated the electric age, then IT and finally cyber-physical systems that can be seen as [a] distinct era because of its velocity, scope and system impact. This is the age of global connections that have the power to transform entire systems of 'production, management and governance'." (Peters 2017, 3).
}

Although, as Schwab $(2016,12)$ claims, in 4IR, "emerging technologies and broad-based innovation are diffusing much faster and more widely than in previous ones", the second industrial revolution has yet to be fully experienced by 17 per cent of the world as nearly 1.3 billion people still lack access to electricity. For him, this is also true for the third industrial revolution, with more than half of the world's population, i.e. 4 billion people, most of whom live in the developing world, lacking access to the Internet (Schwab 2016, 12). The point is, experiencing 4IR does not mean that humans have experienced adequately and equally the previous industrial revolutions. For example, although the Internet has been used widely in African higher education, it is still surprising when some academics prefer to submit hard copies 
of their articles for consideration for publication. In the next section, regarding university teaching and learning, we show that adopting 4IR strategies does not mean that we have exhausted fully what has been characteristic of the previous industrial revolutions. And, as we shall argue, one way of actually making sense of 4IR is to draw on technologies of previous revolutions.

Moreover, considering that higher education institutions play an important role in societal transitions. However, many higher education offerings seem to be geared towards the demands of the past industrial revolutions. The accelerating pace of technological innovation resulted in the shortening of the shelf-life of employees' existing skill sets. During previous industrial revolutions, higher education has often taken decades to offer an answer for the required skill sets required on a large scale. For instance, the Future of Jobs Report (2016), as outlined by the World Economic Forum suggested that the current core curriculum content in 50 per cent of all subject disciplines taught in a four-year technical qualification will be redundant by the time student graduate. Consequently, with the impending skillset disruption and a large proportion of subject discipline knowledge at the risk of being outdated in a few years, higher education institutions are under increased strain to ensure that their graduates will be able to function effectively within society. The Future of Jobs Report specifically highlights complex problemsolving skills as one of the most important skills required to be enacted by graduates. Additionally, social skills (persuasion, emotional intelligence, teaching others), cognitive abilities (creativity and mathematical reasoning) and processing skills (critical thinking) will also be in high demand. Although the Future of Jobs Report outlines the aforementioned key skills demand in 2020, higher education institutions are under increased pressure to anticipate the skills they should equip their graduates with to function within 4IR. This has opened the door for online talent platforms such as LinkedIn to partner with higher education intuitions. Millions of people around the world list their education, experience and skills on LinkedIn. LinkedIn analytics, drawing on a range of algorithms, is able to cluster skills associated with a given profession. As a user of LinkedIn can update her skills within the context of her existing profession, LinkedIn is able to extrapolate which skill set is most pertinent to a profession at any given time. This may afford higher education institutions the foresight to ensure that current offerings remain in congruence with societal demands.

In South Africa, the government through its politico-economic policy, the National Development Plan (NDP) (2011) is quite intent on addressing a major barrier to cultivating higher education in 4IR by providing greater access to the Internet. The NDP $(2011,23)$ states:

"All South Africans should be able to acquire and use knowledge effectively. To this end, the 
institutional arrangements to manage the information, communications and technology (ICT) environment need to be better structured to ensure that South Africa does not fall victim to a 'digital divide'."

Furthermore, South African universities, in particular, are now being challenged by the Ministry of Education to embark on the pursuit of shaping their pedagogical activities in light of the demands of 4IR on the grounds that such educational efforts would hopefully contribute towards economic prosperity, job creation, and empowerment of marginalised communities. In this regard, Professor Tawana Kupe, vice-chancellor of one the leading universities in South Africa, the University of Pretoria, states the following:

"Universities in [South] Africa, as with their counterparts globally, are required to contribute to the advancement and development of their societies. This needs to be underpinned by teaching and learning strategies that create well educated, socially conscious citizens who are equipped with skills for their era, in this case the fourth industrial revolution (4IR)." (Kupe 2019, 1).

Furthermore, Professor Mandla Makhanya, vice-chancellor of the University of South Africa (Unisa) posits the following:

"The Fourth Industrial Revolution in South Africa is not going away, not today, tomorrow or in future .... With job losses estimated to be over 2000, this is a catastrophe for those concerned. How prepared are we for a change that is upon us? As African universities with some reserves, we must surely be the vanguard of the necessary transformation. The world is changing and confusing as it is fully engaged in change and transformation. Academics need to be prepared to deal with transition as we don't know what this world would look like." (Makhanya 2019, cited in Ravhudzulo 2019, 1).

From the above, it seems as if university leaders and the government of South Africa also take the emergence of 4IR technologies seriously, especially in relation to cultivating credible teaching and learning. In our view, technologically informed pedagogic practices should be geared towards engendering socially conscious and responsible citizens who can expand their technological capacities in the interest of building autonomous and deliberative communities of inquiry and change. It is to such a discussion that we now turn.

\section{UNIVERSITY TEACHING AND LEARNING AS A RUPTURED PEDAGOGIC ACTIVITY}

University education as a definitive form of higher education is considered by many African governments to be significant in building stable democratic societies. Since African societies have already made some strides in educating many students and in preparing them to be 
responsible democratic citizens, it seems apt to reconsider the ways universities on the continent educate students in 4IR. Nancy Gleason $(2018,5)$ cogently reminds us:

"HE [higher education] has a crucial role to play in shaping the societal transitions necessary to adjust to the 4IR. But today's HE was designed to meet the needs of past industrial revolutions with mass production powered by electricity. Those systems are not suited for the automation economy. Today's students (of all ages) are faced with major challenges in demographics, population (both growing and shrinking ones), global health, literacy, inequality, climate change, nuclear proliferation, and much more. As students today leave university, the 4IR world has significantly different demands on them than have previously existed."

In light of Gleason's claims, it makes sense to reconsider university teaching and learning at African universities. In our work on university teaching and learning, we argue for ruptured pedagogical practices whereby, firstly, teachers and students engage autonomously and deliberatively as equals in pedagogic spaces of play and attentiveness in order that they (teachers and students) take risks towards cultivating socially just actions (Y. Waghid, F. Waghid and Z. Waghid 2016). Secondly, ruptured pedagogic practices are also attuned to cultivating cosmopolitan reflexivity in order that teachers and students may give their practices an emancipatory impetus, that is, counteracting forms of cultural, political and economic hegemony - a matter of re-imagining higher education as an act of decoloniality (Y. Waghid, F. Waghid and Z. Waghid 2018). Thirdly, university teaching and learning, we argue, also connect teachers and students intra-actionally, which means that the connections between teachers and students are responsive and responsible - a matter of being diffractive (Davids and Waghid 2019). By implication, riskful, reflexive and intra-actional pedagogic encounters are ruptured actions that can most appropriately be enacted with an atmosphere of 4IR.

From the above, we posit that 4IR would not necessarily guide university teaching and learning in ruptured ways. Rather, cultivating ruptured pedagogical practices that remain open to riskful, reflexive and diffractive ways of teaching and learning can most appropriately enhance more credible pedagogic actions commensurate with the demands of 4IR. In other words, if 4IR were to have any meaningful influence on university education, the latter has to become attuned to ruptured actions on the basis that rupturing is intertwined with the ways 4IR technologies can manifest in pedagogical actions. Let us consider at least three ways in which ruptured teaching could manifest in university education. Firstly, artificial intelligence (AI) is a way computer systems are used to imitate human actions, such as Apple's Siri voice assistant, Amazon's Alexa, Uber ridesharing, and Google Translate (Online Learning 2019). In teacher education, one could invite teacher education students to elucidate concepts on the basis of their Google Translate retrievals and then further encourage them to bring into contestation multiple 
understandings of difficult concepts. AI in Education 4.0 - that is, the reference to education enacted in 4IR - represents technological applications as competent in aspects that were previously perceived to be performed primarily through human function (Heaven 2017).

Secondly, in medical education, some university teachers use programmed robots to perform important clinical procedures, such as injections and surgeries. Considering that decoloniality and anti-racism are sometimes perceived by some students as topics that are too sensitive for discussion in teacher education classrooms, the imaginary example of using a robot to "engage" students on challenging socio-political matters pertaining to substantive change might enhance rupturing in their learning as the possibility of teacher bias might be eliminated. In other words, imagine sensitive matters being introduced through robotic teaching and learning. It could be that students will perhaps feel more included than when they have to learn with a teacher whom they might regard as biased in his or her thinking about concepts and practices. Considering the use of automation in teacher education, Rosi Braidotti (2015) reminds us, "it is no longer sufficient to side with the critical [educationa] theory that accuses computation to be reducing human thought to mere mechanical operations". In other words, using robotic teaching should not necessarily be considered opposed to reason on the basis that automation relies on computation, which, in turn, is constituted in reason.

Thirdly, especially in teacher education programmes, teaching through 3D modelling and coloured printed copies of images could bring a particular educational concept to life, and enhance practical problem-solving skills - a form of ruptured learning. Put differently, when students, for example, are initiated into deliberations about poverty and inequality in South African communities, teachers could use 3D images on the basis of which students would be exposed, through virtual reality, to images depicting poverty and unemployment. In this way, students could become more compassionate towards vulnerable others in their learning - a matter of exercising compassionate imagining through seeing and putting oneself in the shoes of vulnerable others.

From the above, it seems possible that the use of technologies in teacher education is one way of enhancing ruptured teaching and learning in an era of 4IR. Of course, digital technologies in itself will not transform university teaching and learning. Rather, teachers and students should be re-skilled to use technologies in multiple ways in the quest to cultivate transformative forms of higher education. However, as we caution in the next section, the latter - that is, re-skilling of teachers and students - implies that university teachers and students should not be remiss of difference and otherness. 


\section{ON THE COSMOPOLITAN HUMAN CONDITION AND 4IR}

Nowadays, university teaching and learning is conceived of as an educational encounter that should respond to the demands of 4IR. The point we are making is that conditions in 4IR are ubiquitous in such a way that teaching and learning as pedagogical encounters at universities can actually be enhanced transformatively. This implies that graduates ought to be initiated into practices whereby their capacities, skills and attitudes will be enhanced not only to function as trained workers in an industrialised economy with acceptable levels of literacy and numeracy but also as democratic citizens in their countries. For many university educators, the latter might imply - wrongly we would argue - that graduates ought to be cultivated along the lines of homogeneity, "weaned away from their socio-cultural particularities into compliance and loyalty to the nation-state" - an idea of education that resonates with colonialism and neocolonialism (Sears 2019, i). Our contention is that university education cannot be focussed parochially on producing literate workers who function in isolation from their particular local and diverse situations and who are merely responsive to universal (global) concerns. Rather, university teaching and learning should be geared towards cultivating a cosmopolitan human condition where teachers and students do not merely conform to universal goals of education through which they acquire global competencies and skills. People (teachers and students) should engage with difference and diversity (Waghid et al. 2019).

If engaging with difference and diversity is central to cosmopolitan education, it implies firstly that students should be taught what it means to engage with ethnic and cultural difference - that is, being initiated into what we refer to as a rooted cosmopolitan education. The upshot is that teaching and learning within 4IR should be seen as fusing digital technologies with our human bodies so that "engaged and effective citizenship that seeks social justice and equity in a complex and diverse world" (Sears 2019, ii) can be cultivated. Secondly, through digital technologies, university education does not only have the potential to be cosmopolitan but also to become more deliberative. In this sense, engaging critically and self-reflexively with one's own values, beliefs and worldviews in relation to difference is recognition of one's own situatedness. Thirdly, when university teachers and students become increasingly engaged in the digital world, there is invariably more pedagogical space for disruption and dissent as a manifestation of the engagement of such teachers and students with otherness. In this way, university education would become connectivist rather than just instructivist, which leaves open the door for more innovative and flexible ways of becoming.

In sum, university teaching and learning cannot be oblivious of the age of 4IR. The recognition of greater heterogeneity, coupled with enhanced forms of deliberative engagements, and the cultivation of dissent and disagreement through digital forms of teaching 
and learning might just augur well for an enhanced form of cosmopolitan (higher) education. As aptly stated by Schwab $(2016,97)-$

"The fourth industrial revolution renders technology an all-pervasive and predominant part of our individual lives, and yet we are only just starting to understand how this technological sea-change will affect our inner selves. Ultimately, it is incumbent upon each of us to guarantee we are served, not enslaved, by technology. At a collective level, we must also ensure that the challenges technology throws at us are properly understood and analysed. Only in this way can we be certain that the fourth industrial revolution will enhance, rather than damage, our wellbeing". (Our emphases).

South African university education is part of the global university community and, considering that the global university community is invariably being transformed as a consequence of major shifts in technological capacity, university teachers and leaders cannot remain oblivious of such changes. University education ought to be guided by ruptured educational theories and practices vis-à-vis 4IR of a rooted kind. In other words, rooted cosmopolitan education implies that university communities ought to bring the particularities into conversation with global developments. This implies that education ought to become more commensurate with what it means to engage autonomously and indigenously, yet technologically and deliberatively in ruptured pedagogic contexts.

\section{REFERENCES}

Braidotti, R. 2015. "Introduction to a lecture by Luciana Parisi, Automated Cognition, Algorithmic Capitalism and the Incomputable." Utrecht University. http://cfh-lectures.hum.uu.nl/automatedcognition-algorithmic-capitalism-and-the-incomputable (Accessed 14 November 2019).

Davids, N. and Y. Waghid. 2019. Teaching and learning as a pedagogic pilgrimage: Cultivating faith, hope \& imagination. London: Routledge.

Future of Jobs Report. 2016. The Future of Jobs: Employment, skills, and workforce strategy for the fourth industrial revolution. http://www3.weforum.org/docs/WEF_Future_of_Jobs.pdf (Accessed 15 November 2019).

Gleason, N. (Ed.). 2018. Higher education in the era of the fourth industrial revolution. Singapore: Palgrave Macmillan.

Heaven, D. 2017. Machines that think. Boston: Nicholas Barley.

Kupe, T. 2019. "Universities are key to 4IR employment." Mail \& Guardian July 19, 2019. https://mg.co.za/article/2019-07-19-00-universities-are-key-to-4ir-employment (Accessed 14 November 2019).

National Development Plan. 2011. National Development Plan - Vision for 2030. Pretoria: Government Printers.

NDP see National Development Plan.

Online Learning. 2019. "Ten Facts about Artificial Intelligence in teaching and learning." https:/teachonline.ca/sites/default/files/tools-trends/downloads/ten_facts_about_artificial_ intelligence.pdf (Accessed 14 November 2019).

Peters, M. A. 2017. "Technological unemployment: Educating for the fourth industrial revolution." 
Educational Philosophy and Theory 49(1): 1-6.

Ravhudzulo, L. 2019. “4IR deepening inequalities in South Africa.” Unisa. https://www.unisa.ac.za/ sites/corporate/default/News-\&-Media/Articles/4IR-deepening-inequalities-in-South-Africa (Accessed 14 November 2019).

Sears, A. 2019. Foreword. In Cosmopolitan education and inclusion: The self in deliberation with others, ed. Y. Waghid, C. H. Manthalu, J. Terblanche, F. Waghid and Z. Waghid, i-iv. New York: Palgrave Macmillan.

Schwab, K. 2016. The fourth industrial revolution. Cologny: World Economic Forum.

Waghid, Y., C. H. Manthalu, J. Terblanche, F. Waghid and Z. Waghid. 2019. Cosmopolitan education and inclusion: The self in deliberation with others. New York: Palgrave Macmillan.

Waghid, Y., F. Waghid and Z. Waghid. 2016. Educational technology and pedagogic encounters. Rotterdam: Sense.

Waghid, Y., F. Waghid and Z. Waghid. 2018. Rupturing African philosophy on teaching and learning: Ubuntu justice and education. New York: Palgrave Macmillan. 